\begin{tabular}{|ccc|}
\hline & ANNALES INSTITUTI SLAVICI \\
& UnIVERSITATIS DEBRECENIENSIS & \\
SLAVICA XLVII & 2018 & DEBRECEN \\
\hline
\end{tabular}

Ольга ФЕдУНИНА

\title{
МЕЖДУ ТАЙНОЙ И ЗАГАДКОЙ: ОТ НАРРАТИВНОЙ СТРАТЕГИИ К ЖАНРУ
}

\section{Between Mystery and Riddle: From Narrative Strategy to Literary Genre}

In the paper a difference is made between the mysterious and the enigmatic as fundamentally different narrative and genre strategies. The first is typical of the so-called novelmystery or the novel-myth, charcterized by the concept of impossible rational comprehension of the mystery explained by the plot. The second represents a vast field of criminal literature, where the plot is dependent on a riddle that has a pre-given answer. The differences between these two types of novels are manifested at all the main levels of poetics, especially in the specific traits of the subject-oriented organization. However, the paper shows that the general strategy of the mysterious is also implemented through different moods in different criminal genres such as classic detective stories, the police novel, the "adventurous investigation", and the "victim-centered investigation". Thus, we can conclude that the mystery and the riddle can reassemble genre constructive strategies not minus then narrative.

Keywords: narrative strategy, narrative intrigue, aenigmatic, mysteric, genre, novel-mystery, novel-myth, criminal literature

Импульсом для обращения к этой теме стали, прежде всего, наблюдения В.И. Тюпы относительно энигматической интриги как чередования «сокрытия и откровения», сопоставленной им с интригой «детективного расследования» [ТюПА 2014: 101]. Подобное неожиданное, казалось бы, сравнение встречается также в работах других исследователей: в известной книге И.П. Смирнова «Роман тайн “Доктор Живаго”» [СмиРнОВ 1996], в статье Е. Фарино с провокационным названием «Что казалось, когда казалось, что...? Статья, из которой читатель легко может узнать все то, что в ней содержится» [ФАРИНО 2015: 73]. Наконец, эта линия продолжается в работе из сборника, посвященного творчеству современной российской писательницы, признанного мастера в области криминальной литературы Александры Марининой [ИВАНОВА 2002: 175].

Приведенные примеры свидетельствуют о том, что сравнение обозначенных явлений востребовано научной традицией. Однако «сокрытие» при реализации соответствующих нарративных интриг может быть связано с разными причинами, узнавание также происходит по-разному, и, наконец, позиции нарратора относительно скрытого смысла также различны. Очевидна необходимость не только сопоставить, но и разграничить два принципа построения нарратива и художественной реальности, в основе которых лежат принципиально непознаваемая до конца тайна и загадка, изначально имеющая свое решение, поиск которого - лишь вопрос способностей героев и развертывания событий 
в пространственно-временных рамках произведения. Я уже пыталась затронуть эту проблему в ее жанровом аспекте [ФЕдунинА 2015]. Повторю здесь наиболее важные аргументы, дополнив их новыми наблюдениями.

Для начала обозначу полюса в заданной системе координат. С одной стороны, на полюсе тайны - так называемые романы-мистерии [SZILÁRD 1989, БАРКОВСКАЯ 1996]. Этот тип романа «характеризуется родовым и жанровым синкретизмом, сложной иерархией уровней содержания, обусловленной рецепцией в символистском творчестве эзотерических (прежде всего теософскоантропософских) идей» [ФИлимОНОВА 2008: 188]. Однако наиболее важным отличительным признаком представляется именно сюжет, построенный по принципу мистерии как посвящения и требующий особого типа героя, а также особой субъектной организации и пространства-времени. Если использовать выражение А. Филимоновой, «путь индивида к цельности через мистическое приобщение к трансперсональному духовному опыту, перерождение его в качестве “иного" (инициация)» [ФилимОНОВА 2008: 204] приобретает в романе такого типа основополагающее значение и определяет его поэтику на всех основных уровнях.

В этом контексте можно также говорить о романе-мифе, который определяется Б.М. Гаспаровым следующим образом: «...миф превращается в реальность, но и реальность тем самым превращается в миф. Исчезает всякая временная и модальная (“действительность vs. недействительность”) дискретность, один и тот же феномен, будь то предмет, или человеческий характер, или ситуация, или событие, существует одновременно в различных временных срезах и в различных модальных планах» [ГАСПАРОВ 1994: 28-29]. Кстати, роман Булгакова «Мастер и Маргарита» рассматривается исследователями и как роман-миф, и как роман-мистерия, что заставляет задуматься о близости этих понятий. Так, Е. Миллиор прямо говорит, что «Мастер и Маргарита» - «пасхальная мистерия, завершающаяся апофеозом» [МиллиОР 1995: 106]. Б.М. Гаспаров трактует финальное воскресение героя в этом романе как его пробуждение [ГАСПАРОВ 1994: 65].

С другой же стороны, на полюсе загадки, открывается обширная и неоднородная в жанровом отношении область криминальной литературы. В самом деле, в романе Б. Пастернака, как убедительно показывают в своих работах В.И. Тюпа и Г.А. Жиличева, воплощается нарративная стратегия откровения, посредством которого герою открывается «конечная тайна» жизни и смерти (насколько она вообще может быть постигнута) [ТюПА 2014], [ЖИличЕВА 2013, 195-281]. Здесь невозможно успешное раскрытие этой тайны путем логических умозаключений. Вспомним булгаковского Мастера с его «О, как я все угадал!» [БУлГАКОВ 1990, 132].

Такое «угадывание» (как синоним откровения), не основанное на строгом анализе фактов, совершенно чуждо Шерлоку Холмсу или Пуаро как классическим сыщикам. Здесь принципом, организующим нарратив и сюжет, стано- 
вится именно загадка, обязательно предполагающая отгадку. Ответ изначально существует наравне с условиями задачи и лишь до определенного момента в развитии повествования и сюжета неизвестен всем или ряду персонажей, а порой не входит и в кругозор нарратора. Примечателен следующий пассаж из «Собаки Баскервилей» А. Конан Дойля: «-Мы, кажется, вступили в область догадок ["We are coming now rather into the region of guesswork", CONAN DOYLE 1998: 33], - заметил доктор Мортимер.

- Скажите лучше, в область, где взвешиваются все возможности, с тем, чтобы выбрать из них наиболее правдоподобную. Таково научное использование силы воображения, которое всегда работает у специалистов на твердой материальной основе» [КОНАН ДойЛь 1966: 35].

В такой художественной системе вполне закономерно замыкание процесса познания и его предмета в условно-реальной области, без выхода за ее пределы; рефлексия над этим совершенно очевидна в следующих словах Холмса: «Я борюсь со злом по мере своих скромных сил и возможностей, но восставать против самого прародителя зла будет, пожалуй, чересчур самонадеянно с моей стороны» [КОНАН ДойЛь 1966: 25]. Меняется и представление о смерти: из «конечной тайны» она превращается в элемент загадки, которая должна быть решена лишь в своих внешних, не экзистенциальных пределах: кем, как и по какой причине было совершено убийство?

В произведениях, где реализуется нарративная стратегия откровения, рациональные объяснения не только не нужны, но в полной мере даже невозможны. От героя требуется как раз полное приятие «непонятных» событий в их непреложной данности; напомню слова Воланда, обращенные к Берлиозу перед первым вставным нарративом о Пилате: «И доказательств никаких не требуется <..> Все просто: в белом плаще с кровавым подбоем» [БУЛГАКОВ 1990: 19] и т.д. Более того, такая система требует и особого героя. Если же он, подобно рассказчику в романе Фаулза «Маг» (The Magus), пытается разгадать мистериальную тайну как загадку, как логическую связь причин и следствий, его неизбежно ждет поражение. Именно изображением цепи таких безуспешных попыток добраться до первопричины таинственных событий характеризуется нарратив в «Маге».

На этом можно было бы остановиться. Но тесная взаимосвязь речевого уровня с законами мира героев, которые диктует, условно говоря, литература maйны, и с особым характером соотношения этого изображенного мира и действительности автора / читателя, в той или иной степени причастного к открывшемуся герою откровению, заставляет нас вплотную подойти к вопросу о жанровом значении этого аспекта в бахтинском понимании. Согласно M.M. Бахтину, «каждый жанр способен овладеть лишь определенными сторонами действительности, ему принадлежат определенные принципы отбора, определенные формы видения и понимания этой действительности, определенные степени широты охвата и глубины проникновения» [МЕДВЕДЕВ 2003: 143]. В самом деле, мы видели на примере «Мастера и Маргариты» Булгакова и «Мага» Фаулза, что изображаемая действительность не может быть постигнута 
рациональным образом и что картина мира коренным образом отличается от представленной в том же классическом детективе Конан Дойля. Соответственно, помимо простого разграничения двух принципов, о которых идет речь, следует также исследовать их жанрообразующую функцию. Как пишет И.П. Смирнов, «литература загадывает нам загадки. Это ее общее свойство. Однако она бывает более и менее таинственной. Когда она утрирует это, конститутивное для нее, свойство, оно делается жанрообразующим» [СМИРНОВ 1996: 21].

В криминальной литературе представлен совершенно другой способ построения нарратива, нежели в произведениях, где реализуется нарративная стратегия тайны (откровения). Перед нами два разных типа «неизвестного» (тайна и загадка) и соответственно два типа познания: нерассудочного, путем откровения - и с помощью логических умозаключений на основе анализа известных фактов или улик. В первом случае субъект пассивен, ибо «парадоксальным образом, тайна сама приближается к субъекту откровения» [ЖИлИчЕВA 2014, 229]. Во втором случае он не может не принимать активного участия в процессе расследования, поскольку самостоятельно продуцирует разгадку, которая в идеале должна сойтись с изначально заложенными условиями задачи. Н.Н. Вольский отграничивает «детектив» от близких ему жанров именно по наличию загадки, обязательно имеющей отгадку, которая должна быть найдена с помощью логического мышления [Вольский 2006: 13].

Однако дело в том, что этот идеальный вариант, очевидно, характерен не для всех жанров криминальной литературы; или, точнее, возможность найти исчерпывающий ответ на загадку в разной степени реализуется в них. Представляется, что именно с этим, а вовсе не с отсутствием загадки, связаны принципиальные различия, которые отмечает Н.Н. Вольский. И.П. Смирнов считает, что «детективные романы и рассказы отличаются от остальных текстов о тайне главным образом тем, что рисуют такой таинственный мир, для которого невозможно самоозначивание, самораскрытие, коль скоро автореференция угрожала бы преступнику лишением жизни или свободы. Тайна в детективном повествовании разоблачается извне» [СмиРнОВ 1996, 26]. «Самораскрытие» загадки преступления действительно невозможно в классическом детективе, где установление истины является прерогативой «великого сыщика», который априори не может провалить дело. Даже в тех случаях, когда этот провал кажется неизбежным, счастливая «случайность» спасает положение. Яркий пример - уже упоминавшаяся повесть А. Конан Дойля «Собака Баскервилей», где вместо сэра Генри погибает переодетый в его одежду беглый каторжник.

Коль скоро загадка преступления может быть в полной мере разгадана только «великим сыщиком», обстоятельства дела и ход расследования обязательно разъясняются самим сыщиком, чей кругозор неизменно оказывается шире, чем у всех остальных персонажей. Это финальное объяснение, встроенное обычно в своего рода сцены-«конклавы» (Л.П. Гроссман), является особой, инвариантной для классического детектива композиционно-речевой формой. Обозначенные принципы соблюдаются везде, возьмем мы в качестве примера «Знак четырех» и «Собаку Баскервилей» Конан Дойля или «Убийство 
на поле для гольфа» А. Кристи из серии, посвященной Пуаро, или «Труп в библиотеке» из серии о мисс Марпл и т.д.

Иное соотношение загадки и ее возможности быть отгаданной представлено в другом жанре криминальной литературы - «авантюрном расследовании», впервые описанном в таком качестве Н.Н. Кириленко. Выявленный исследовательницей принцип неполного установления истины и открытого финала явным образом контрастирует с характерными чертами жанровой структуры классического детектива, о которых говорилось выше: «Отсюда открытый финал, когда часть тайн станет известна “когда-нибудь, может быть” < ..> в то время как классический детектив всегда образует кольцо» [КИРИЛЕНКО 2012: 89]. Здесь всегда несколько субъектов, ведущих расследование, причем некоторые из них могут обладать информацией о деле, недоступной к этому моменту развития сюжета основному сыщику. Характерный пример - «Любовница смерти» Б. Акунина, подтверждающая сохранность константных жанровых признаков и на современном этапе существования «авантюрного расследования». В романе действуют как минимум четыре субъекта расследования: Эраст Петрович Фандорин, чья настоящая фамилия, правда, не называется в тексте, но легко угадывается читателем; Маша Миронова (Коломбина); журналист Лавр Жемайло (Сирано); ZZ, осведомитель полиции (Гораций, доктор Вельтман). Именно этот последний изначально обладает куда большей полнотой информации, чем Фандорин, но не имеет доказательств против преступника и потому не раскрывает его личность полиции: «Лишь тогда, когда мне удастся раздобыть верные улики, я выдам Вам и имя, и адрес Дожа» [АКУнин 2004: 58].

Такая раздробленность, отмеченная в более ранних образцах «авантюрного расследования» Н.Н. Кириленко («Преступление в Орсивале» и «Дело № 113» Э. Габорио, «Тайна Желтой комнаты» Г. Леру и др.), напрямую связана с порой сомнительной успешностью главного героя в роли сыщика. Фандорину не удается предотвратить целую серию смертей, несмотря на все его исключительные, с точки зрения других персонажей, качества: «Наши заседания все больше напоминают фарс, но смеяться не хочется. Слишком много т-трупов. Я таскаюсь в этот нелепый клуб уже три недели, а результат нулевой. Нет, что я говорю! Не нулевой - отрицательный! У меня на глазах погибла Офелия, Лорелея, Гдлевский, Сирано. Я не смог их спасти» [АКунин 2004: 188-189]. Соответственно, в финальной схватке с преступником и Фандорин, и Гораций (наиболее успешные сыщики) также проигрывают: первый попадает в ловушку, второй поддается гипнозу. Исход схватки решает судьба: Дож пьет кислоту вместо водки, ибо так повернулось колесо рулетки. Особая роль случая в раскрытии дела сближает этот жанр с полицейским романом.

Сыщики в полицейском романе являются профессионалами, но они не гениальны, как в классическом детективе. Соответственно, они действуют в мире случайностей, порой раскрывая дело благодаря неожиданно найденной улике или признанию преступника: «Знаешь, Стасов, когда я думаю о том, накаком тонюсеньком волоске немыслимых случайностей иногда подвисает наша сы- 
щицкая удача, мне не по себе делается» (А. Маринина, «Чужая маска») [МАРИНИНА 1999: 323]. Для раскрытия дела здесь нужна и «помощь» преступника: так, в романе Дж. Берка «Неоновый дождь» напрямую говорится о том, что преступников чаще всего удается поймать не в результате расследования, а потому что они сами дают ключ к разгадке (ср. с аналогичными примерами из романов «Человек на балконе» П. Вале и М. Шеваль, «Блондинка в бетоне» М. Коннелли). Одновременно возрастает и роль интуиции полицейского в успешном завершении расследования. Однако в целом представление о возможности установить истину здесь совершенно иное, чем в классическом детективе: «И вы тут сидите и разглагольствуете об истине и тому подобном? Когда вы в последний раз видели правдивый полицейский отчет? Когда вы в последний раз давали подлинную информацию, запрашивая ордер на обыск? Так что не говорите мне о правде. Хотите правды - отправляйтесь к священнику или к кому-нибудь в этом роде» («Блондинка в бетоне» Коннелли) [КОНнЕЛли 2008: 175].

В связи с этим завершение расследования в полицейском романе далеко не всегда влечет за собой полное восстановление нормального течения жизни героев. Видимый успех сыщиков уравновешивается гибелью напарников, близких, как, к примеру, в «Эре милосердия» братьев Вайнеров. Спорным также является вопрос об успешности расследования из-за невозможности самостоятельно найти разгадку или убедительные доказательства вины преступника. Характерный пример - «Розанна» П. Вале и М. Шеваль, где расследование убийства молодой женщины длится более полугода, но при этом полиции удается обнаружить преступника лишь благодаря счастливой случайности и помощи американского коллеги: «Они будут вспоминать это дело, но вряд ли с гордостью» [ВАЛЕ-ШЕВАЛЬ 2011: 349]. В этом смысле показательны также романы А. Марининой из цикла о Каменской, в частности, «Смерть и немного любви», «Когда боги смеются», «Мужские игры». В полицейском романе зло не может быть побеждено раз и навсегда; за каждым закрытым делом следует новое преступление, расследование которого является профессиональной обязанностью героев: «Бреммера навсегда упрячут в тюрьму, но вскоре на его место явится кто-нибудь другой. И так до бесконечности. Черное сердце никогда не бьется в одиночку» [КОННЕЛЛИ 2008: 380].

В этом отношении еще один криминальный жанр, названный мной по типу сыщика «расследованием жертвыl» [ФЕДУнинА 2012], как раз не предполагает серийность. Для потенциальной жертвы преступления, вынужденной вести расследование для спасения собственной жизни, столкновение с такой смертельной загадкой уникально. В этом заключается еще одно принципиальное отличие от классического детектива и «авантюрного расследования». Поиск решения обычно не изображается здесь как цепь в полной мере осознанных и активных поступков «следователя», направленных на «установление личности преступника, его мотивов» [ТАМАРЧЕНКО 2008: 55]. Скорее, усилия жертвы найти разгадку становятся вынужденным ответом на действия преступника. Назову в качестве примеров роман Э.Л. Уайт, вышедший в русском переводе под названием «Винтовая лестница» [УАЙт 1991], [WHITE 1933], «Танцующий 
детектив» У. Айриша, «Седьмой уровень» Миюки Миябэ и др. Потенциальная жертва не столько проводит расследование, сколько ограничивается смутными ощущениями и подозрениями. Истина чаще устанавливается в результате случайного стечения обстоятельств или после прямого признания преступника, как это происходит, например, в «Винтовой лестнице» Э.Л. Уайт и «Кривом домишке» А. Кристи. Возможен также вариант, когда жертва погибает, так и не убедившись в правильности своих подозрений («Дурной глаз» Буало-Нарсежака, «Увидеть Лондон и умереть» П. Александра и М. Ролана).

Существенным образом отличается также нарративная структура, характерная для произведений этого жанра. Все события показываются, как правило, с точки зрения «следователя-жертвы»; часто он является также основным субъектом речи («Танцующий детектив» У. Айриша, «Лесная смерть» Б. Обэр). В таком случае, согласно терминологии В. Шмида, здесь появляется диегетический нарратор, который «фигурирует в двух планах - и в повествовании (как его субъект), и в повествуемой истории (как объект)» [Шмид 2003: $81]$ и который в своей второй ипостаси, в отличие от классического детектива, является основным и самостоятельным субъектом расследования. Его далеко не всеобъемлющий кругозор отнюдь не перекрывает кругозоры других персонажей, включая преступника, как в классическом детективе; жертва не обладает какими-то исключительными способностями, как авантюрный сыщик, или специальными знаниями, подобно сыщикам в полицейском романе. Зато читатель получает возможность искать разгадку личности и мотивов преступника «одновременно» с героем, не полагаясь на обязательную счастливую развязку, ибо, по замечанию Ц. Тодорова, «момент повествования $<\ldots>>$ совпадает с действием. Ни один черный роман не представляется в форме воспоминаний: там нет той исходной точки, с которой нарратор бросает взгляд на прошедшие события, мы не знаем, доберется ли он живым до конца истории» [TODOROV 1971, 1978. Пер. с франц. мой. - О.Ф.].

Степень успешности жертвы в роли сыщика, как и в других уже рассмотренных криминальных жанрах, напрямую связана с перемещением акцента с логического начала на интуитивное угадывание истины. В романе Б. Обэр «Лесная смерть» героиня, постоянно составляя разные куски «головоломки», все же не может самостоятельно собрать всю картину целиком. Для жертвы картина мира остается раздробленной вплоть до того момента, когда преступница сама выдает себя во время заключительной схватки. Оценка убийцы весьма недвусмысленна: «Ну и долго же до вас все доходит!» [ОБЭР 2011: 281]. Как для классического детектива необходимо финальное объяснение «великого сыщика», так для «расследования жертвы» - саморазоблачение преступника, без которого жертва чаще всего не в состоянии найти разгадку. Соответственно, и восстановление нарушенной действиями преступника нормы возможно лишь частично даже после установления личности убийцы и исчезновения опасности. В романе А. Левина «Щепка» после завершения расследования героиня-жертва вдруг начинает по собственному почину повторять действия преступника (подглядывать за жильцами дома). 
Подводя итоги всего сказанного, еще раз подчеркну, что тайна и загадка, а также предзаданный ими способ постижения истины совершенно по-разному организуют повествование, определяя все важнейшие аспекты поэтики произведения: тип героя, субъектную организацию, сюжет, картину мира и характер тематического завершения (по М.М. Бахтину). Таким образом, можно говорить о двух различных нарративных стратегиях тайны и загадки, по которым выстраиваются, по выражению Г.А. Жиличевой, «и способы воздействия на читателя ${ }^{1}$, и приемы презентации наррации, и особенности событийного ряда» [ЖИличЕВА 2013: 282]. Первая была убедительно описана В.И. Тюпой и Г.А. Жиличевой; выделить вторую и обозначить ее специфику я попыталась применительно к криминальной литературе, учитывая необходимые различия реализации этой стратегии в разных жанрах. Однако говорить о проблеме жанра в этом ключе можно и применительно к полюсу тайны, в частности, к роману-мистерии и роману-мифу, сама жанровая структура которых, очевидно, требует определенной нарративной стратегии. Более подробное исследование этого вопроса и уточнение понятий требует дальнейшей работы.

\section{Литература}

Акунин 2004: Акунин, Б. Любовница смерти. Серия: Новый детективъ. Москва: Захаров. БАРКОВСКАЯ 1996: Барковская, Н.В. Поэтика символистского романа. Екатеринбург: УрГПУ.

БулГАКОВ 1990: Булгаков, М.А. Мастер и Маргарита. В кн.: Булгаков, М.А. Собрание сочинений в 5 тт. Т. 5. Москва: Художественная литература 7-386.

ВАЛЕ-ШеВАЛЬ 2011: Вале, П., Шеваль, М. Розанна. Перевод В. Злобина, Е. Рымко. Москва; Санкт-Петербург: ИД Домино.

Вольский 2006: Вольский, Н.Н. Загадочная логика: детектив как модель диалектического мышления. В кн.: Вольский, Н.Н. Легкое чтение: работы по теории и истории детективного жанра. Новосибирск: Издательство НГПУ, 4-126.

ГАСПАРОВ 1994: Гаспаров, Б.М. Из наблюдений над мотивной структурой романа М.А. Булгакова «Мастер и Маргарита». В кн.: Гаспаров, Б.М. Литературные лейтмотивы. Очерки по русской литературе XX века. Москва: Восточная литература, 28-82.

ЖиличевА 2002: Жиличева, Г.А. Тайники, завесы, покровы, откровения. В кн.: Поэтика «Доктора Живаго» в нарратологическом прочтении. Москва: Intrada, 211-230.

ЖиличевА 2013: Жиличева, Г.А. Нарративные стратегии в жанровой структуре романа (на материале русской прозы 1920-1950-х гг.). Новосибирск: НГПУ.

ИвАнОВА 2002: Иванова, Н. От детектива к саге: Александра Маринина в контексте современной не только литературной ситуации. В кн.: Творчество Александры Марининой как отражение современной российской ментальности. Москва: ИНИОН РАН, 167-176.

КиРИлЕнКО 2012: Кириленко, Н.Н. «Авантюрное расследование» или классический детектив. В: Новый филологический вестник. 2012. Вып. 2 (21), 80-95.

КонАн Дойль 1966: Конан Дойль, А. Собака Баскервилей. Пер. Н. Волжиной. В кн.: Конан Дойль, А. Собрание сочинений в 8 тт. Т. 3. Москва: Правда, 1966. С. 5-166.

1 Вопросы о программировании читательских ожиданий, а также связи между понятиями нормы и тематического завершения в криминальной литературе уже затрагивались мной ранее [ФЕДУНИНА 2013]. 
КОннЕлли 2008: Коннелли, М. Блондинка в бетоне. Пер. с англ. С.Б. Певчева. Москва: АСТ: АСТ Москва: Хранитель.

МАРИНИНА 1999: Маринина, А. Чужая маска. Москва: ЭКСМО-Пресс.

МЕДВЕДЕВ 2003: Медведев, П.Н. [Бахтин, М.М.] Формальный метод в литературоведении. Критическое введение в социологическую поэтику. Москва: Лабиринт, (Бахтин под маской).

МиллиОР 1995: Миллиор, Е. Размышления о романе М. Булгакова «Мастер и Маргарита». В: Вестник Удмуртского университета. Вып. III.77-129.

ОБэр 2001: Обэр, Б. Лесная смерть. Пер. с франц. Е. Капитоновой. Санкт-Петербург: Лимбус Пресс.

СмиРнов 1996: Смирнов, И.П. Роман тайн «Доктор Живаго». Москва: Новое литературное обозрение.

ТАМАРЧЕНКО 2008: Тамарченко, Н.Д. Детективная проза. В кн.: Поэтика: словарь актуальных терминов и понятий. Москва: Издательство Кулагиной - Intrada, 55-56.

ТюПА 2014: Тюпа, В.И. Нарративная стратегия романа. В кн.: Поэтика «Доктора Живаго» в нарратологическом прочтении. Москва: Intrada, 76-104.

УАЙт 1991: Уайт, Э.Л. Винтовая лестница. Пер. с англ. Р. Шидфара. В: Смена. Вып. 5. 176-273.

ФАРИнО 2015: Фарино, Е. Что казалось, когда казалось, что...? Статья, из которой читатель легко может узнать все то, что в ней содержится. В кн.: Диалог согласия. Москва: Intrada, 71-77.

ФЕДУнинА 2012: Федунина, О.В. «Следователь-жертва» в криминальной литературе: к вопросу о типологии героя и жанра. В: Новый филологический вестник. Вып. 2 (21). 130-141.

ФЕДУНИНА 2013: Федунина, О.В. Категория имплицитного читателя в криминальной литературе (постановка проблемы). B: Narratorium: междисциплинарный журнал. 2013. Вып. 1-2 (5-6). http://narratorium.rggu.ru/article.html?id=2631073 (дата обращения 4.05.2015).

ФЕДУНИНА 2015: Федунина, О.В. Тайна и загадка в нарративной структуре: жанровый аспект. В кн.: Диалог согласия. Москва: Intrada, 127-135.

ФилимоновА 2008: Филимонова, А. Мифологизм и мистерия в символистском романе Андрея Белого («Крещеный китаец»). B: Acta Slavica Iaponica. 2008. Vol. 24. 188-204.

Шмид 2003: Шмид, В. Нарратология. Москва: Языки славянской культуры.

CONAN DOYLE 2005: Conan Doyle, A. The Hound of the Baskervilles. Another Adventure of Sherlock Holmes. Series: The Oxford Sherlock Holmes. Edited with an Introduction and Notes by W.W. Robson. Oxford University Press, UK.

SzILÁRD 1989: Szilárd, L. A karnevalelmélet Vjacseszlav Ivanovtól Mihail Bahtyinig. Budapest: Tankönyvkiadó.

TODOROV 1971, 1978: Todorov, Tz. Poétique de la prose (choix) suivi de Nouvelles recherches sur le récit.

http://www.ae-lib.org.ua/texts/todorov_poetique_de_la_prose_fr.htm (accessed 4.05.2015).

WHITE 1933: White, E.L. Some Must Watch. London; Melbourne: Ward, Lock and Co.

Ольга ФЕДУНИНА

Russian State University for Humanities

Moscow, Russia

fille.off@gmail.com 